\title{
Japanese contribution to in-situ meteoroid and debris measurement in the near Earth space
}

\author{
Hajime Yano* \\ Earth Science and Solar System Exploration Division, NASA Johnson Space Center, Mail Code SN2, Houston, TX 77058, U.S.A.
}

(Received October 8, 1998; Revised March 22, 1999; Accepted March 27, 1999)

\begin{abstract}
This paper reviews major results of present studies and recent developments for future missions in the Japanese space program regarding in-situ measurement and collection of micrometeoroids and orbital debris in the near Earth space. Japan's contribution in this area began with the post flight impact analysis of the Space Flyer Unit (SFU) satellite which was returned to Earth in 1996 after 10-month exposure in space. Despite a decade later than similar efforts first conducted in the USA and Europe, it resulted in a record of over 700 hypervelocity impact signatures, which now forms the nation's first database of real space impacts being open to public in the Internet. Together with laboratory impact tests, both morphological and elemental analyses of the impact craters yielded new insights of the meteoroid to debris ratio as well as flux variation compared with the previous spacecraft. The next step was a passive aerogel exposure in the STS-85 shuttle mission in 1997. No hypervelocity impact was found there but its experience has been incorporated for designing a microparticle collector to be on-board the Japan Experiment Module-Exposed Facility of the International Space Station. All of such "passive" collection of micro-impact features, however, still leave the significant uncertainty in the quest of their origins. Therefore an aerogel-based "hybrid" dust collector and detector (HD-CAD) is currently under the development. It measures time of impact and deduces impactors' orbital and physical parameters by detecting impact flash while still capturing them intact. The system is suitable for both (1) sample return missions in LEO as well as to parent bodies of meteoroids, i.e., comets and asteroids, and (2) one-way mission to where the thermal and plasma environment is such that impact induced plasma detectors may suffer from significant noise, e.g., a Mercury orbiter and a solar probe. Together with unambiguous dust samples from a comet by STARDUST and an asteroid by MUSES-C as references, the HD-CAD in the LEO will be able to deduce the accretion rates of the cometary and asteroidal dust grains on the Earth.
\end{abstract}

\section{Introduction: A Brief History of the Microme- teoroid Research in Space}

Despite its immensely significant contribution to the Solar System sciences, conventional meteorite research is always subject to luck of sample discoveries, unavoidable selection biases and chemical and physical alterations by interaction with the Earth environment. Micrometeorites collected from stratosphere, polar ice cores, and deep sea and in-land sediments also suffer from similar selection effects in terms of size, shape, magnetism, time resolution, etc., but to a lesser extent. If one wishes to eliminate all those obstacles in sampling unbiased extraterrestrial materials before interaction with the Earth environment (except its gravity enhancement and its spatial shielding of the meteoroid influx), in-situ measurement and collection of micrometeoroids in the near Earth space is the alternative. It can tell us about influx of extraterrestrial materials to the Earth at the smallest size regime at the present epoch. Such fluxes are largely governed by current balances of their respective sources and sinks from their

*Present address: Planetary Science Division, Institute of Space and Astronautical Science, 3-1-1 Yoshinodai, Sagamihara, Kanagawa 229-8510, Japan.

Copy right $($ C The Society of Geomagnetism and Earth, Planetary and Space Sciences (SGEPSS); The Seismological Society of Japan; The Volcanological Society of Japan; The Geodetic Society of Japan; The Japanese Society for Planetary Sciences. parent bodies, e.g., comets, asteroids, Kuiper Belt Objects, ejecta from planets and satellites and interstellar particles. Recent major discoveries of planetary sciences are closely related to the cosmic dust studies, such as dust disks around extra-solar planetary systems, pre-solar grains embedded in carbonaceous chondrites, Kuiper-Belt Objects, circumsolar asteroidal dust ring, large structures of cometary dust trails, and interstellar dust particles penetrating to the inner region of the Solar System. Thus understanding of origins, evolution and current state of the microparticulate population has become indeed a fundamental prerequisite for that of the Solar System.

However, the history of space measurement of dust grains began with a more operational reason than the scientific motivation. It started at the dawn of the space age, right after the Sputnik launch some 40 years ago, in order to assess risks of spacecraft paused by hypervelocity impact consequences due to meteoroids (e.g., McDonnell, 1978). Also, as the human space activity expands, an increasing threat of orbital debris hazards has required us continuous, in-situ measurement of the microparticulate environment in the near-Earth space (e.g., National Research Council, 1995). Thus, both "active detectors" and "passive collectors" of microparticles in space have been employed for most of interplanetary probes and retrievable spacecraft in the Low Earth Orbit (LEO) in the past, for the benefits of both the Solar System sciences and 
Table 1. Prospects of currently funded/selected in-situ cosmic dust studies and minor body exploration missions in 1996-2012 (as of November, 1999) Keys $=$ Sample Returns, Active/Passive Dust Experiments, and Minor Body Visits. For the acronyms, refer the Appendix A.

\begin{tabular}{|c|c|c|}
\hline Year & Japanese Programs & Other Nations (e.g., NASA \& ESA) \\
\hline 1996 & -SFU-Post Flight Analysis ( 2000) & 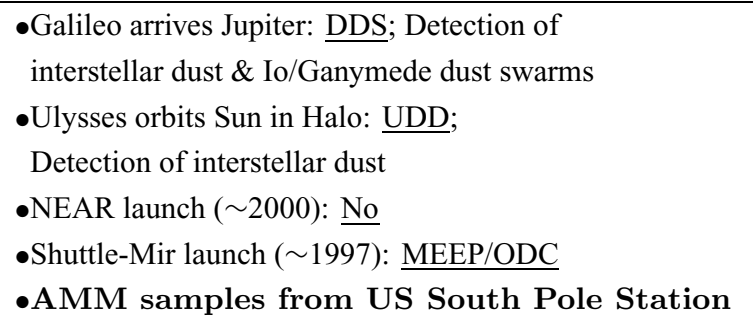 \\
\hline 1997 & $\begin{array}{l}\text { •JARE-37 (1995 ): AMM samples } \\
\text { arrive Japan from Dome Fuji } \\
\text { •STS-85: MFD/ESEM Aerogel } \\
\text { •JARE-39 ( 1999): 1st AMM expedition }\end{array}$ & $\begin{array}{l}\text {-NEAR Mathilde flyby } \\
\text { •Cassini/Huygens launch ( 2003): CDA } \\
\text { •Shuttle-Mir MEEP/ODC Aerogels retrieved }\end{array}$ \\
\hline 1998 & $\begin{array}{l}\text {-Nozomi launch }(\sim 2004) \text { : } \underline{\text { MDC }} \\
\text { •Leonid MAC }(\sim 1999) \text { : HD-TV flux \& } \\
\text { Meteoric cloud observation }\end{array}$ & $\begin{array}{l}\text {-MGS Phobos close-up } \\
\text { - Galileo Jupiter Gossamer Ring flyby } \\
\text { - Galileo Jovian small inner satellites flyby } \\
\text { (Metis, Adrastea, Amalthea, and Thebe) } \\
\text {-Deep Space-1 launch }(\sim 1999+): \underline{\text { No }} \\
\text { - Leonid meteoroid shower }(\sim 2002): \text { MAC } \\
\text {-ISS construction starts }(\sim 2003) \\
\text {-NEAR Eros flyby }\end{array}$ \\
\hline 1999 & $\begin{array}{l}\text {-JARE-39 AMMs arrive Japan } \\
\text {-JARE-41 ( 2001):2nd AMM expedition }\end{array}$ & $\begin{array}{l}\text {-STARDUST launch ( 2006): Aerogel, CIDA, DFM } \\
\text {-Deep Space-1 Braille flyby }\end{array}$ \\
\hline 2000 & & $\begin{array}{l}\bullet N E A R \text { Eros rendezvous } \\
\bullet \text { STARDUST interstellar dust collection-1 }\end{array}$ \\
\hline 2001 & $\begin{array}{l}\text { •JARE-41 AMMs arrive Japan } \\
\text { •ISS-Russian Service Module } \\
\text { aerogel samples return to Earth }(\sim 2003) \text { : MPAC }\end{array}$ & $\begin{array}{l}\text { (•Genesis launch }(\sim 2003) \text { : No }) \\
\bullet D S-1 \text { possible extended mission to fly-by Comets } \\
\text { Wilson-Harrington \& Borrelly }\end{array}$ \\
\hline 2002 & $\begin{array}{l}\bullet \text { MUSES-C launch }(\sim 2006): \underline{\text { No }} \\
\text { •JEM-EF operation starts }(\sim 2012): \underline{\text { SEDA/MPAC }}\end{array}$ & $\begin{array}{l}\text {-CONTOUR launch ( 2008): CIDA } \\
\text {-STARDUST interstellar dust collection-2 }\end{array}$ \\
\hline 2003 & $\begin{array}{l}\text {-MUSES-C arrives Nereus or 1989ML; } \\
\text { Surface material sampling } \\
\text { •Nozomi arrives Mars; Detection of Martian } \\
\text { dust torus near Phobos and Deimos } \\
\text { •JEM-EF SEDA/MPAC samples } \\
\text { return to Earth } \\
(\bullet \text { Lunar-A launch }(\sim 2004): \underline{\text { No }}) \\
(\bullet \text { SELENE launch }(\sim 2004): \underline{\text { No }})\end{array}$ & $\begin{array}{l}\bullet \text { CONTOUR Comet Encke flyby } \\
\bullet \text { Rosetta launch }(\sim 2011): \text { DFA, CIDA, COSIMA } \\
\bullet \text { Cassini/Huygens arrives Saturn/Titan } \\
\text { (•Genesis Solar Wind Particle samples } \\
\text { return to Earth) }\end{array}$ \\
\hline 2004 & & $\begin{array}{l}\text {-Deep Impact Launch }(\sim 2005): \underline{\text { CIDA }} \\
\text {-STARDUST Comet Wild-2 flyby; Cometary dust collection }\end{array}$ \\
\hline 2005 & $\begin{array}{l}\text {-Mercury Orbiter launch }(\sim 2008) \text { : } \\
\text { Hybrid Dust Detector, MOS }\end{array}$ & $\begin{array}{l}(\bullet \text { Mars Sample Return launch }(\sim 2008): \text { No?) } \\
\bullet \text { Deep Impact Comet Tempel-1 encounter }\end{array}$ \\
\hline 2006 & •MUSES-C samples return to Earth & $\begin{array}{l}\text {-STARDUST samples return to Earth } \\
\text {-CONTOUR Comet Schwassman-Wachmann-3 flyby }\end{array}$ \\
\hline 2007 & & -Rosetta Mimistrobell flyby \\
\hline 2008 & -Mercury Orbiter arrives Mercury & $\begin{array}{l}\bullet \text { CONTOUR Comet d'Arrest flyby } \\
\bullet \text { Rosetta Shipka flyby } \\
\text { (•Mars samples return to Earth) }\end{array}$ \\
\hline 2009 & & \\
\hline 2010 & & \\
\hline 2011 & & -Rosetta Comet Wirtanen rendezvous \\
\hline 2012 & & -Rosetta Comet Wirtanen landing \\
\hline
\end{tabular}


Table 2. Opportunities for cosmic dust studies and parent body sample returns in 1996-2012 (as of November, 1999). Italics indicate the Japanese contributions.

\begin{tabular}{ll}
\hline \multicolumn{1}{c}{ Research Strategies } & \multicolumn{1}{c}{ Missions/Spacecraft } \\
\hline Active In-situ & $\bullet$ Galileo (Jupiter) \\
Cosmic Dust Measurements & $\bullet$ Ulysses (Solar System Halo) \\
in the Interplanetary Space (9) & $\bullet$ Cassini (Saturn) \\
& $\bullet$ Nozomi (Mars) \\
& $\bullet$ STARDUST (Comet) \\
& $\bullet$ CONTOUR (Comets) \\
& $\bullet$ Rosetta (Comet and NEOs) \\
& $\bullet$ Deep Impact (Comet) \\
& $\bullet$ ISAS Mercury Orbiter (Mercury) \\
\hline Major Passive In-situ & $\bullet$ SFU-PFA \\
Cosmic Dust Collections and & $\bullet$ Mir-MEEP/ODC \\
Post Flight Analyses in LEO (4) & $\bullet$ HST-PFA \#3 \\
& $\bullet$ ISS-JEM-EF-SEDA/MPAC \\
Parent Body Sample Returns (2) & $\bullet$ STARDUST \\
& $\bullet$ MUSES-C \\
\hline
\end{tabular}

the advancement of the human space activities. Especially in the next 15 years, one of the major focal interests in the planetary exploration is minor bodies in association with the local dust environment of different parts of the Solar System. Table 1 summarizes currently funded/selected missions for such studies as well as sample return opportunities of micrometeoroids and micrometeorites both in the Japanese and international space programs. In 1996-2012, up to 8 comets and 12 asteroids (including 6 small satellites of Mars and Jupiter) will be visited, two of which are planned for sample returns (see the later section for more details); 9 interplanetary space probes will conduct active dust measurements in the various parts of the Solar System from the orbit of Mercury to that of Saturn; 4 major passive dust collection or post flight impact investigations in the LEO are also in progress or in preparation (Table 2). It is clear that the importance and thus also research opportunities in in-situ measurements and collection of cosmic dust will increase as these programs will be carried out. The Japanese scientific community is expected to contribute this field, too.

From the start of the space shuttle era, post flight analyses (PFA) of retrieved components or whole bodies of large and long exposure spacecraft have been carried out. Their list includes NASA's Solar Maximum Mission satellite (SMM) (Warren et al., 1989) and Long Duration Exposure Facility (LDEF) (See et al., 1990), ESA's European Retrievable Carrier (EuReCa) (UniSpace Kent et al., 1994), and the Hubble Space Telescope (HST) solar cell array (SCA) of NASA and ESA (Space Application Services et al., 1995; Yano, 1995). Together with laboratory experiments and computer simulations of hypervelocity impacts to correlate between crater and impactor dimensions, they provided abundant data and revised our insights of the microparticulate environment in the LEO. For instance, the LDEF data enabled to estimate the current annual accretion rate of extraterrestrial materials as $(40 \pm 20) \times 10^{3}$ tons with a peak of $\sim 200 \mu \mathrm{m}$ diameter (Love and Brownlee, 1993) while the flux of the meteoroids that left residues of analyzable size for the energy dispersive X-ray analyzer (EDX) inside the crater on metal targets exceeds non-aluminium orbital debris at the ratio of $\sim 9: 5$ (Yano, 1995).

\section{SFU-Post Flight Analysis \\ 2.1 General overview}

The PFA of Japan's first retrievable satellite Space Flyer Unit (SFU) follows this "lineage" to better understand the LEO dust environment (Kuriki et al., 1997). Launched by the H-II rocket in March 1995, SFU was retrieved in January 1996 during the space shuttle mission STS-72 (Fig. 1). The spacecraft had orbited the Earth at an operational altitude of $\sim 480 \mathrm{~km}$ and an inclination of $28.5^{\circ}$ in a total of 301 days. It had an octagonal cross section of $\sim 4.5 \mathrm{~m}$ in diameter by $3.0 \mathrm{~m}$ height. Its total exposed area was $\sim 146 \mathrm{~m}^{2}$ although its two solar arrays of $\sim 50 \mathrm{~m}^{2}$ each were jettisoned due to a failure of latching signals during its retrieval (Fig. 2). Except for its first month, devoted to an infrared telescope operation, its attitude control was such that solar cells always faced to the Sun while one of the solar array paddles pointed to the ecliptic northern hemisphere. Thus there was a face $(+Z)$ preferentially headed to the apex of the Earth's heliocentric motion. This makes the direction of orbital debris impacts, which are bound to the geocentric co-ordinates, to appear randomized.

The SFU-PFA focused on large, flat surfaces made of uniform components with a small influence of local shielding by other parts of the spacecraft body. Its systematic impact flux studies included (1) aluminized Kapton multi-layer insulation (MLI) made of 12 layers of Kapton films and Dacron nets (Fig. 3a), (2) silvered Teflon radiators glued on 2024-T81 Al plate (second surface mirrors [SSM]; Fig. 3b), on peripheral, Sun-pointing and anti-Sun faces and, (3) painted Al plates like scuff plates and external panels of some experiments.

In a total of $\sim 28 \mathrm{~m}^{2}$ scanned area, over 700 hypervelocity impact signatures were discovered and recorded. It includes 


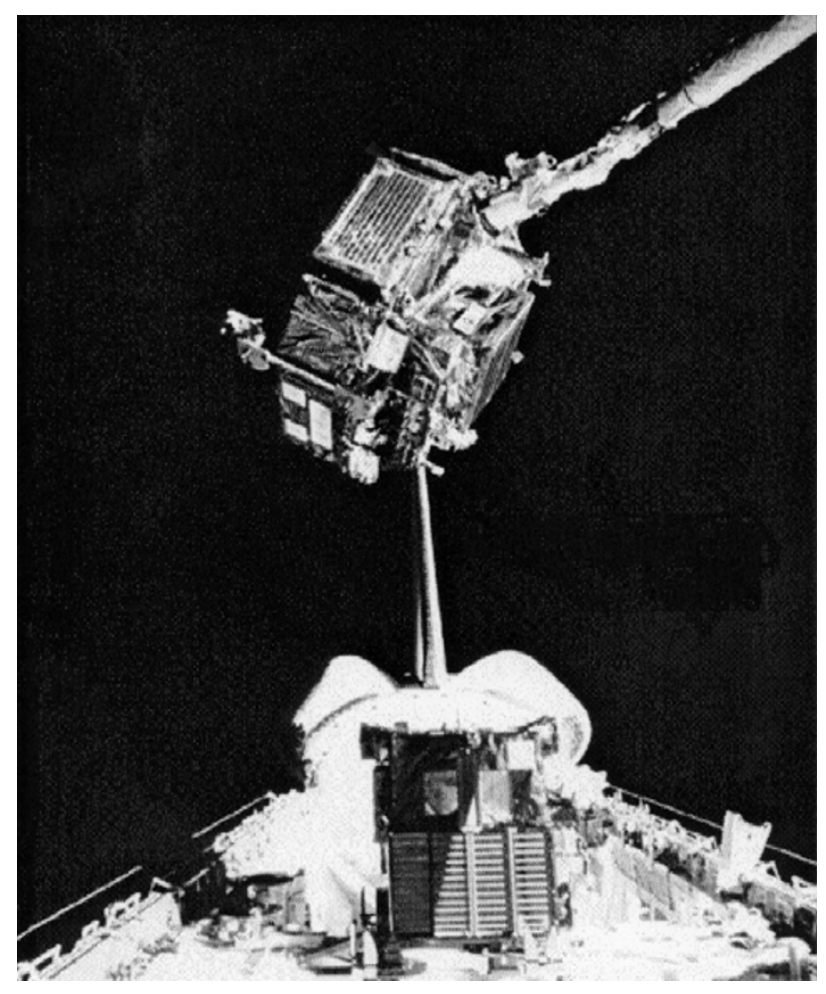

Fig. 1. Space Flyer Unit spacecraft at its retrieval in the STS-72 (Photo Courtesy: NASA).

a "clustered streak" of $\sim 50$ hypervelocity impact holes concentrated in some $100 \mathrm{~cm}^{2}$ area on a MLI near a reaction control system (RCS) thruster, possibly due to the secondary impact ejecta.

Impact craters on SSMs and penetration holes on MLIs were studied in detail on their morphological types, sizedependent fluxes and elemental compositions of their impact residues. Details of the PFA operation including the contamination control and the initial findings were reported elsewhere (Deshpande et al., 1997a; Yano et al., 1997; Kibe et al., 1997). By using X-ray CT scan and laser microscope, three dimensional analysis of impact crater profiles on the SSMs and the number of penetrated layers of the MLIs were also studied to constrain physical parameters of impactors (i.e., size, density, impact velocity, etc.) (Morishige et al., 1999; Yano et al., 1999). The SSM impact craters were classified into four types $(\mathrm{A} \sim \mathrm{D})$ depending upon degree of damages (Kibe et al., 1997).

Cross calibration tests for the same materials used for the SSM, MLI, Al alloys and solar cells have been carried out on a light gas gun at $\sim 5 \mathrm{~km} / \mathrm{s}$ (Neish et al., 1997) and the Van de Graaff accelerator at $\sim 10 \mathrm{~km} / \mathrm{s}$. In compliance with the agreement made in the Inter-Agency Debris Coordination (IADC) group by major space agencies all over the world to exchange information and to promote collaboration in the meteoroid and debris research, the initial data have been made available to public and continuously updated in the "SFU Meteoroids and Debris Data Archive" homepage at the URL http: / / www . nal .go.jp/www-e/juuten/ kyoten/SFU/SFU.html (Deshpande et al., 1997b).

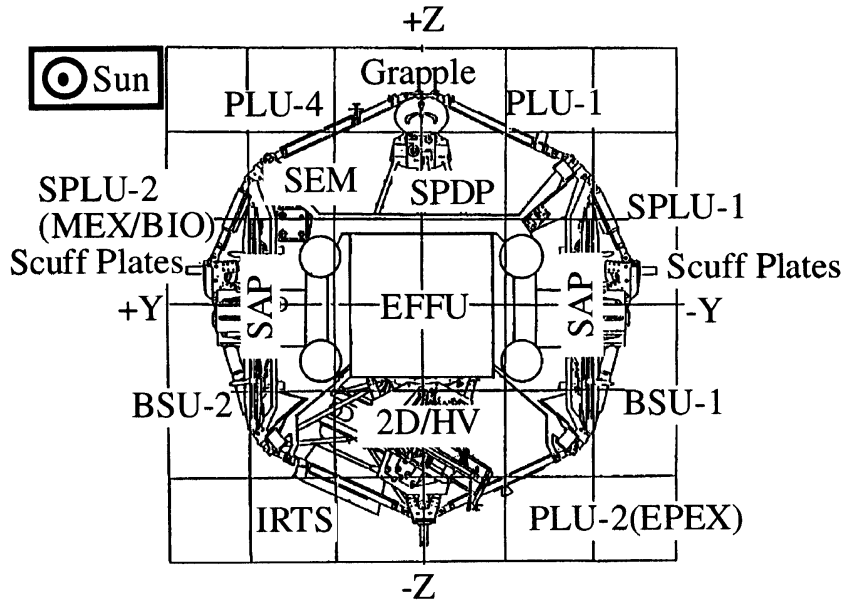

Fig. 2. SFU configuration (solar cell arrays folded) viewed from the Sun pointing face.

\subsection{Elemental analysis of impactor residues}

Semi-qualitative elemental analysis of residues on the SSMs and MLIs were conducted to determine origins of the impactors by using the JEOL JSM 5310LV system, a low vacuum-scanning electron microscope (LV-SEM) and EDX, which did not require conductive coating for imaging such that samples for subsequent detail analyses would not suffer from artificial contamination and deposition (Yano et al., 1998). For routine scanning, its acceleration voltage was 15 $\mathrm{kV}$ in $20 \mathrm{~Pa}$ vacuum level and collection time was $100 \mathrm{sec}-$ onds. All sites were sampled inside, lip and outside of impact craters or holes and judged from the all the data combined. As for the MLI, each penetration was examined the impact lip and its surroundings on the "back" side of the "top" layer and the "front" side of the "bottom" layer that impactor remnants and molten fragments of upper layers were deposited in order to avoid counting the surface contamination. To be consistent with chemical analyses of the previous spacecraft PFAs, the analysis also adapted the classification of major spectra for meteoroids and debris proposed for the LDEF Al clamps and intercostals (Zolensky et al., 1993) and the EuReCa Al foils (Yano et al., 1996), except any peaks produced by background materials, such as F and $\mathrm{C}$ for the Teflon SSM, $\mathrm{C}$ and $\mathrm{O}$ for the Kapton MLI with $\mathrm{Cu}$ and $\mathrm{Zn}$ for brass sample holders. Also excluded were Al and Si for the large SSM impacts which craters reached to the Al substrate and the Si-based adhesive underneath the Teflon layer.

Figure 3 shows a LV-SEM/EDX image and spectra of a typical micrometeoroid (M) impact. With $\mathrm{M}$ and orbital debris (D) origins, impacts were classified into four more categories. "FeS-Si" means that impacts indicate only these three elements, which might well be metallic sulfide meteoroids although $\mathrm{S}$ was occasionally included in terrestrial contamination so that it could also be steel debris. "No Residues (N)" means that impacts left no residues large enough to be detected by SEM/EDX. "Undetermined (U)" is a class that indicated several peaks but lacked or added some elements in order to be judged their origins. This might be due to depletion or fractionation of particular elements by melting and vaporization of the impactors. "Contamination Only 


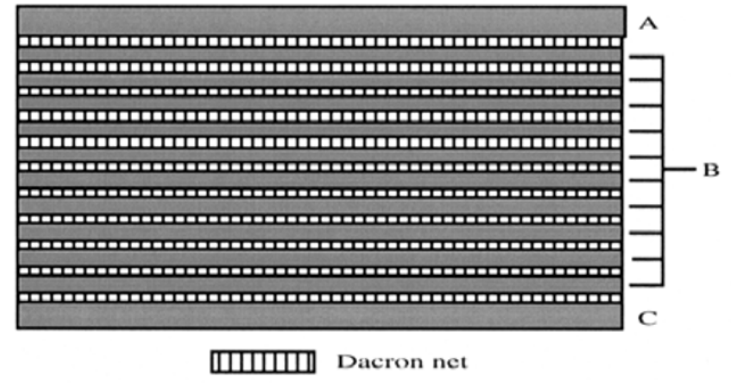

A: 1 layer $\mathrm{x} T=50.8-\mu \mathrm{m}$ aluminized Kapton (Top); Coated on the inside surface

B: 10 layers $\mathrm{x} T=7.62-\mu \mathrm{m}$ Kapton layers

C: 1 layer $\mathrm{x} T=25.4-\mu \mathrm{m}$ Kapton

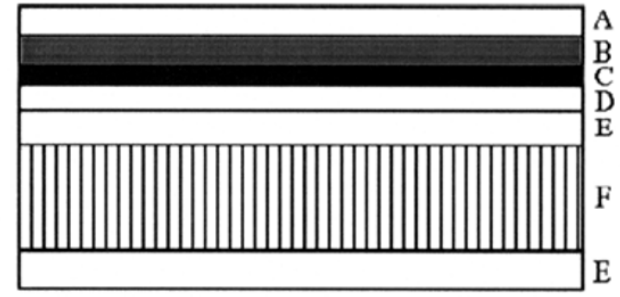

A: FEP Teflon tape; thickness(T) $=127 \mu \mathrm{m}$ (Top)

B: Silver; $\mathrm{T}=1,500 \AA$

C: Inconel; $\mathrm{T}=275 \AA$

D: $3 \mathrm{M}-966$ acrylic adhesive; $\mathrm{T}=51 \mu \mathrm{m}$

E: 2024-T81 Aluminium plate; $\mathrm{T}=381 \mu \mathrm{m}$

F: 5056 Aluminium honeycomb; $\mathrm{T}=20 \mathrm{~mm}$

Fig. 3. Schematics of cross-section of (left) the multi-layer insulation (MLI) and (right) second surface mirrors (SSM) of the SFU spacecraft.
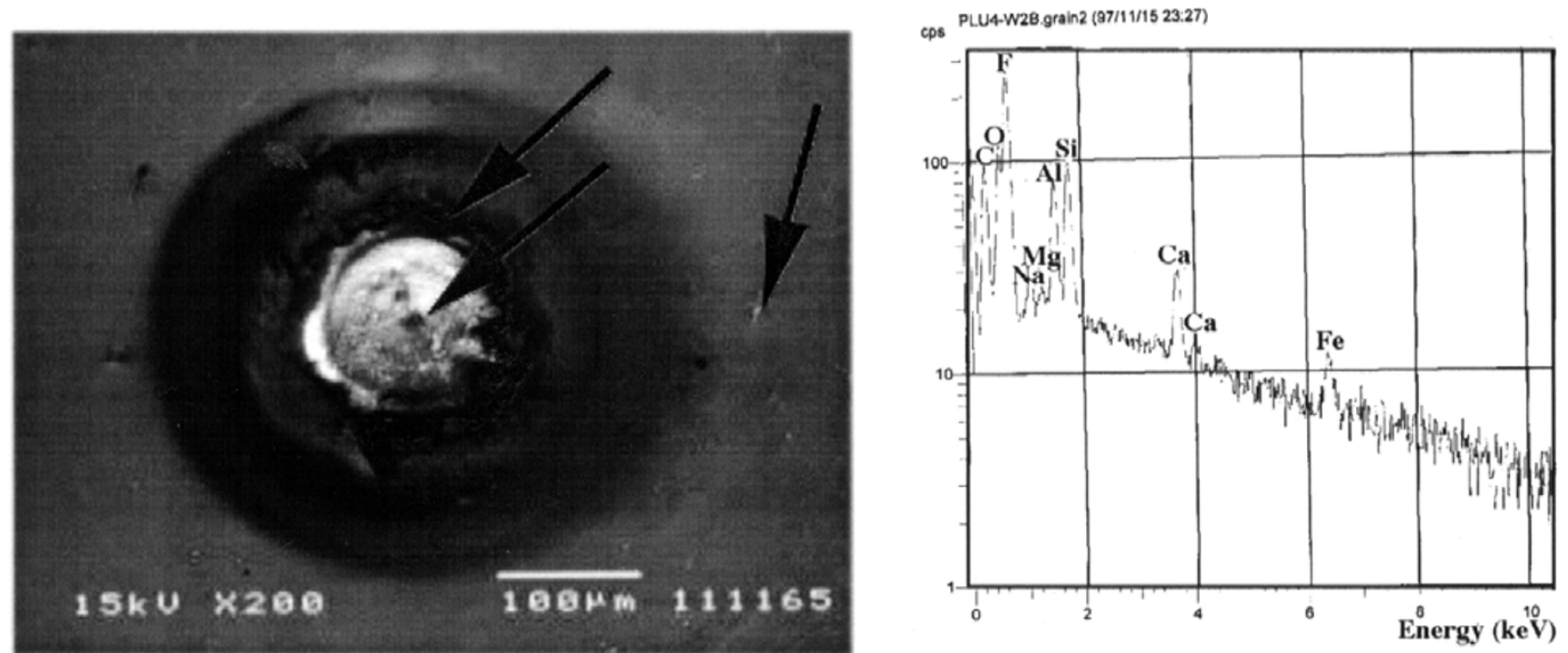

Fig. 4. SEM image and EDX spectra indicating meteoritic features of the SSM crater PLU4-W2B. Arrows indicate inside the crater, on the lip and on a flat target surface outside the crater, where the spectrum were acquired to distinguish real residue signals from the background contamination. The spectra above was taken from the central region of the crater bottom.

(C)" means that craters indicate only elements coming from contaminants; it is a "contaminated N class". Typical contamination for the SSM surfaces were $\mathrm{Na}$ and $\mathrm{K}$ associated with $\mathrm{Cl}$. If $\mathrm{Cl}$ is missing, they might be solid $\mathrm{Na} / \mathrm{K}$ droplet debris like ROSAT coolant leak (though in a different altitude). However one cannot rule out sea breeze formed salt crystals inside the craters after the landing as observed on the LDEF surfaces (Bernhard et al., 1995). If $\mathrm{P}$ and $\mathrm{S}$ were present (Carbon could not be separated from background), they might be faster impacts of waste dump from the space shuttle orbiter during the SFU retrieval; Deshpande et al. (1997a) found several "liquid splash" marks, indicative of slow impact by such droplets, with these elements on the SSM surface.

In total of the $114 \mathrm{SSM}$ impacts, $11 \mathrm{Al}$ fragments, 6 Stainless steels, and $1 \mathrm{Ti}$ paint flake were identified for the D class. Combined with the three-dimensional analysis, it was found that denser debris (e.g., stainless steel) formed deeper craters than less dense ones (e.g., Al). However it should be reminded that all the $\mathrm{Al}$ fragments could be identified in small craters that penetrated the top Teflon layer only, but did not reach to the Al substrate. Stainless steel debris were found in all the crater types regardless their sizes and depths. Consequently, meteoroids and debris shared $7.0 \%$ and $15.8 \%$, respectively, with $1.8 \%$ of FeS-Si among the SSM impacts (Fig. 4; Yano et al., 1999). These numbers should be regarded as the lower limit of the ratio of each class.

For the MLIs, of $~ 384$ impacts in $10.4 \mathrm{~m}^{2}$ scanned area, only a few impacts were perforated all the layers proving the MLI worked as an efficient "capture cell" to trap impactor residues inside (Fig. 5). LV-SEM/EDX analysis was performed for 56 MLI impacts on the Sun-pointing, Anti-Sun and peripheral (Earth's Anti-apex) faces (Fig. 6). Though the sampling numbers are low in the Sun and Anti-Sun faces, the meteoroid to debris ratios on the Sun and peripheral faces were similar to each other. This is not surprising because both faces receive randomized debris components and sporadic meteoroids equally, but do not have flux enhancements 

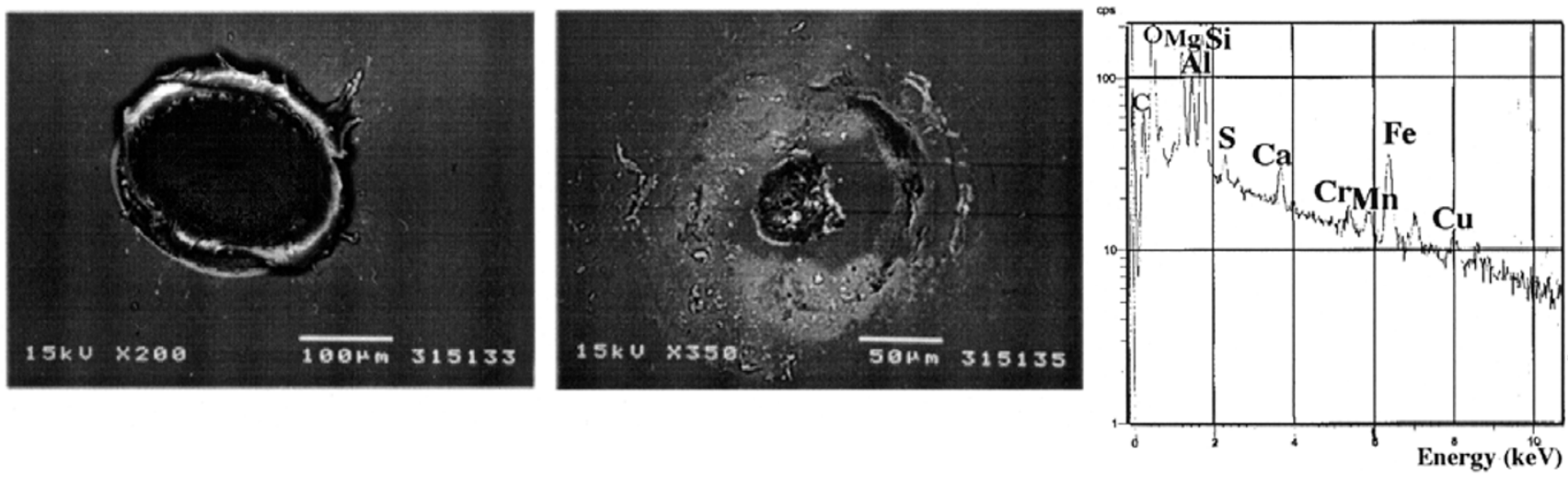

Fig. 5. SEM images of the back side of the top layer (above left) and the front side of the fourth layer with residues (above right) of MLI penetration PLU2-m2-24 and its EDX spectra showing meteoritic features (right).

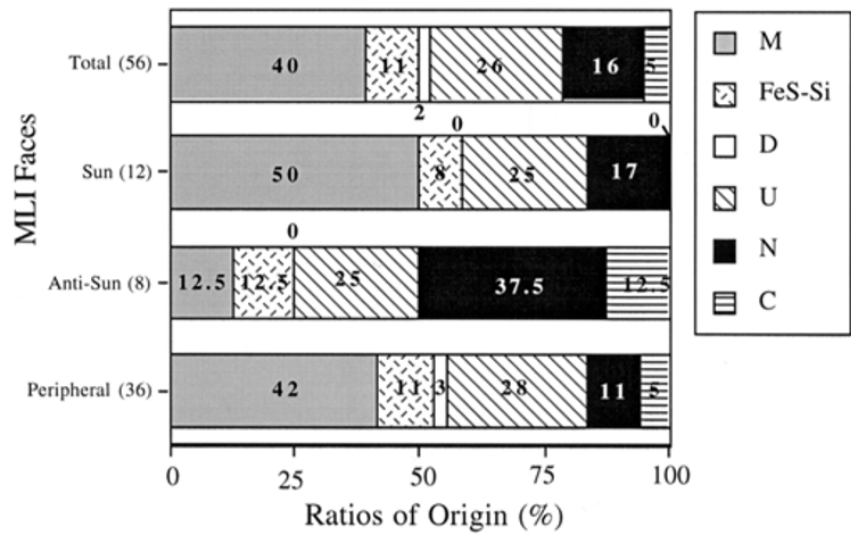

Fig. 6. Ratios of the origin of MLI impactors by pointing faces. ( ) indicates the number of samples. Keys = M: meteoroids, $\mathrm{D}=$ orbital debris, $\mathrm{U}$ : undetermined, $\mathrm{N}$ : no residues, $\mathrm{m} \mathrm{C}$ : contamination only.

of meteoroids from the Earth apex. However, it must be noted that the MLI film was coated with Al so that we could not identify Al-based debris, which was the majority of the D class for the SSM impacts. Thus some Al-based debris might have been included within the $\mathrm{N}$ class. Also noted was that there were more FeS-Si impacts than the SSM. The FeS-Si inside MLI is most likely to be metallic sulfide meteoroids than Fe-based debris because there was much less contamination (C) included sulfur inside the MLI than the SSM surface. Indeed, Graham et al. (1997) classified this type as plymineralic meteoroid impacts on their HST solar cell cover glass samples by using back-scattered electron and X-ray imagery. In total, the MLI holds M for $39.3 \%$ with FeS-Si for $10.7 \%$, (non Al-based) $\mathrm{D}$ for $1.8 \%$, and $\mathrm{N}$ for $16.1 \%$.

Figure 7 and Table 3 compare SFU with elemental analyses of the previous spacecraft impacts from 1980-1993. The CIMMS (Chemical and Isotopic Measurements of Micrometeoroids using SIMS) experiment on LDEF utilized a secondary ion mass spectrometer (SIMS) to investigate the EDX-N class and enabled $\sim 95 \%$ of them to be determined origins (Amari et al., 1993). It proved that LDEF received mostly natural impacts on the trailing face (west) and de- bris on the leading face (east). Except the LDEF CIMMS and HST cells described above, the rest were analysed by SEM/EDX (Yano, 1995). As a result, roughly about a half of impacts were unknown origin while meteoroids were found in a range of $10 \sim 30 \%$. For the SFU-MLI, it goes up to $\sim 50 \%$ if $\mathrm{M}$ and $\mathrm{FeS}-\mathrm{Si}$ are combined. And even if we assume that all the $\mathrm{N}$ and $\mathrm{C}$ classes are due to debris impacts, natural origin still exceeds them, at least in the range of hole diameter (Dh) of 51-748 $\mu \mathrm{m}$. In reality, some of $\mathrm{N}$ impacts may be natural origin which did not leave any residues due to too high impact velocity or/and volatile components like cometary grains. Laboratory experiments demonstrated that more than $90 \%$ of $50-100 \mu \mathrm{m}$ sized micrometeorites from Antarctic ice cores survived impacts on thick Al plates at $\sim 5$ $\mathrm{km} / \mathrm{s}$ and left sizable residues without any significant elemental depletion (Yano et al., 1996). This implies that, if these $\mathrm{U}$ and $\mathrm{N}$ impacts were due to "chondritic" type micrometeoroids which were originally similar to ones found in the Antarctic ice cores (e.g., Maurette et al., 1994) but depleted relatively light elements like $\mathrm{Mg}$ and $\mathrm{S}$ during their impacts on SFU, their impact velocities must have been significantly faster than $\sim 5 \mathrm{~km} / \mathrm{s}$. This scenario favors comets (especially ones with a retrograde orbit) as the origin of these microparticles, rather than main belt asteroids, as some previous studies also suggested (e.g., Graham et al., 1998).

\subsection{Time variation of impact flux}

Figure 8 compares the impact flux of SFU with those of LDEF, EuReCa, and HST all in the Sun-pointing faces, which were converted their impact crater diameters to Fmax, the equivalent maximum thickness of an aluminium plate for marginal perforation to be occurred by a non-oblique hypervelocity impact (Yano et al., 1999). We adopted each of Fmax conversion factor for $\mathrm{Dh}$ on the LDEF Al foils by McDonnell and Sullivan (1992), for inner crater diameter (Dc) on the LDEF Al thick targets by Yano (1995), and for conchoidal fracture diameter (Dco) on the EuReCa and HST solar cell cover glasses by Taylor et al., (1999), respectively. Although a largely accepted empirical conversion factors of Kapton to Fmax is not yet available, the SFU-MLI data was plotted with Dh as a reference because our cross calibration impact experiments up to $\sim 5 \mathrm{~km} / \mathrm{s}$ showed that the Kapton Dh sizes do not exceed the Al Fmax within a factor of $\sim 5$ 


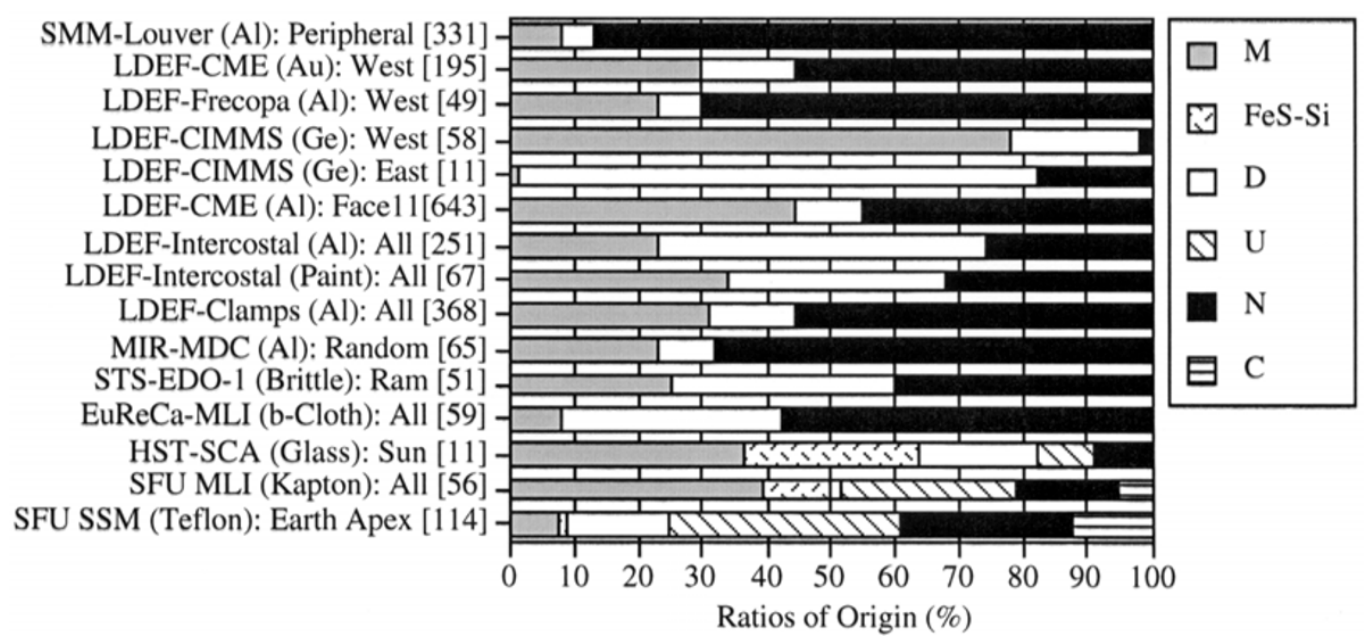

Fig. 7. Summary of ratios of impactor origins of retrieved spacecraft judged by elemental analyses. For details, refer Table 3. From left to right, each column shows spacecraft-experiment/exposed surface (target material): facing direction [number of samples].

Table 3. Classifications and ratios of impactor origins of experiments and PFAs of exposed surfaces on the retrieved spacecraft in the past, judged by EDX elemental analyses $(*=$ except CIMMS which were examined by SIMS). HST and SFU are adopted from Graham et al. (1997) and SFU data from Yano et al. (1999), respectively. The rest were compiled by Yano (1995).

\begin{tabular}{|c|c|c|c|c|c|c|c|c|c|c|}
\hline Spacecraft & $\begin{array}{l}\text { Experiment/ } \\
\text { Surface }\end{array}$ & $\begin{array}{l}\text { Target } \\
\text { Material }\end{array}$ & $\begin{array}{l}\text { Pointing } \\
\text { Direction }\end{array}$ & $\begin{array}{l}\text { Total No. } \\
\text { Samples }\end{array}$ & M (\%) & FeS-Si (\%) & $\mathrm{D}(\%)$ & $\mathrm{U}(\%)$ & N (\%) & $\mathrm{C}(\%)$ \\
\hline SMM & Louver & $\mathrm{Al}$ & Peripheral & 331 & 8 & & 5 & & 87 & \\
\hline \multirow[t]{8}{*}{ LDEF } & $\mathrm{CME}$ & $\mathrm{Au}$ & West & 195 & 30 & & 14 & & 56 & \\
\hline & & $\mathrm{Al}$ & Face 11 & 643 & 44 & & 11 & & 45 & \\
\hline & Frecopa & & West & 49 & 23 & & 7 & & 70 & \\
\hline & CIMMS* & $\mathrm{Ge}$ & & 58 & 78 & & 20 & & 2 & \\
\hline & & & East & 11 & 1 & & 81 & & 18 & \\
\hline & Intercostal & Painted Al & All & 67 & 34 & & 34 & & 32 & \\
\hline & & $\mathrm{Al}$ & & 251 & 23 & & 51 & & 26 & \\
\hline & Clamps & & & 368 & 31 & & 13 & & 56 & \\
\hline MIR & MDC & $\mathrm{Al}$ & Random & 65 & 23 & & 9 & & 68 & \\
\hline STS & EDO-1 & Brittle & Ram & 51 & 25 & & 35 & & 40 & \\
\hline EuReCa & MLI & $\beta$-Cloth & All & 59 & 8 & & 34 & & 58 & \\
\hline HST & Solar Cells & Glass & Sun & 11 & 36.4 & 27.3 & 18.2 & 9.1 & 9.1 & 0.0 \\
\hline \multirow[t]{2}{*}{ SFU } & MLI & Kapton & All & 56 & 39.3 & 10.7 & 1.8 & 26.8 & 16.1 & 5.4 \\
\hline & SSM & Teflon & Earth Apex & 114 & 7 & 1.8 & 15.8 & 36.0 & 27.2 & 12.3 \\
\hline
\end{tabular}

including the maximum error range. Permitting this limitation that may leads a slight shift along the $\mathrm{X}$-axis, all the four spacecraft match their mass distribution index in the size regime of the SFU MLI Dh. For the smaller regions, LDEF flux exceeds EuReCa and HST, both of which agree with each other in the error range. This means that as large impacts at Fmax $>\sim 50 \mu \mathrm{m}$, where meteoroids are expected to exceed debris population from the model prediction, seem to have constant fluxes in 1984-1996, whereas the flux of smaller impacts at Fmax $<\sim 50 \mu \mathrm{m}$ in the median epoch of 1984-1990 seems up to a factor of $\sim 4$ higher than that in the median epochs of 1989-1993 and of 1992-1993. One possible explanation of this is that small debris exceeding meteoroid flux in the size regime were shortened their orbital lifetimes and deorbited by the expanded upper atmosphere during the last solar activity maximum at a peak of 1990 (see a related work by McDonnell et al., 1997).

\section{Aerogel Exposure on a Space Shuttle Orbiter}

As already stated, there are still about a half of microcraters on the past retrieved spacecraft that left no analyzable residues within EDX sensitivity limits and therefore the 


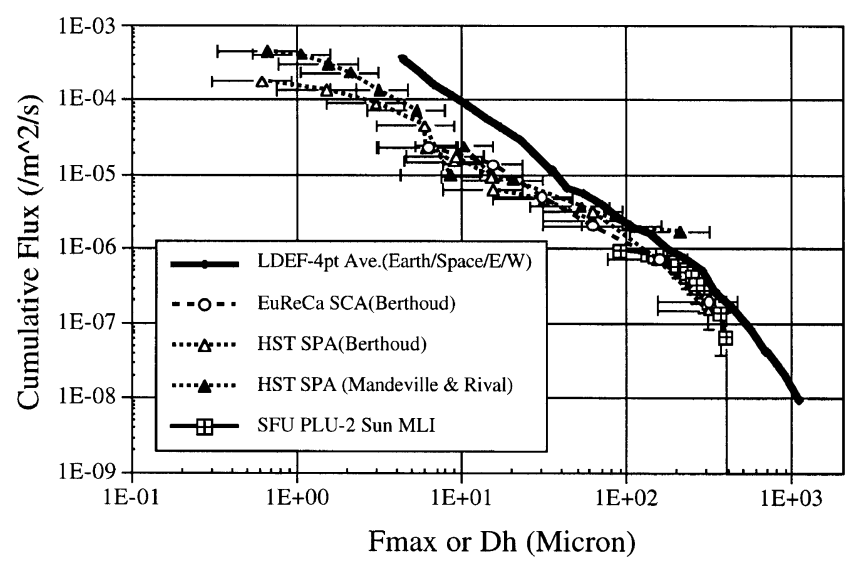

Fig. 8. Comparison of impact fluxes on the Sun pointing faces of LDEF, EuReCa, HST and SFU. All but SFU (MLI Dh) were converted to Fmax $(\mu \mathrm{m})$, the maximum thickness of an aluminium plate for marginal performation due to hypervelocity impacts. Empirical conversion formulae were adopted from McDonnell and Sullivan (1992), Yano (1995) and Taylor et al. (1999).

corrected ratio between meteoroids and debris is yet undetermined. Following opportunistic PFAs for studying origins of microparticles, intact capture of meteoroids and debris with the least destructive fashion is the next logical step for subsequent analyses of elements, mineralogy, petrology, size, structure and bulk density of the captured particles. Since the early 1990's, ultra-low dense materials such as micropore foams and amorphous silica aerogels were deployed in space on-board the space shuttle orbiter (e.g., Maag and Linder, 1992; Tsou, 1995), the EuReCa satellite (e.g., Brownlee et al., 1994; Burchell et al., 1999) and Mir Space Station (e.g., Hörz et al., 1998). Being optically transparent (easy to locate and extract trapped particles), of very low density $\left(0.1-0.01 \mathrm{~g} / \mathrm{cm}^{3}\right)$, but nevertheless proven in the space environment (robust against vacuum and extreme temperatures: thermal conductivity of $\sim 15 \mathrm{~mW} / \mathrm{m}-\mathrm{K}$ at $1 \mathrm{~atm}$ ), aerogel has been used more often than micropore foam. Also the aerogel is high purity $\mathrm{SiO}_{2}$ which does not severely harm post retrieval chemical analysis and capsulates trapped particles which are kept relatively uncontaminated. These advantages have made aerogels to be used as a collection medium for cometary and interstellar dust grains by the STARDUST mission (Vellinga et al., 1997).

During the space shuttle STS-85 mission in August 7-19, 1997, the National Space Development Agencies of Japan (NASDA) flew four modules of $10 \mathrm{~cm} \times 10 \mathrm{~cm}$ area with $2 \mathrm{~cm}$ depth made of aerogel blocks with $0.030 \pm 0.005 \mathrm{~g} / \mathrm{cm}^{3}$ density in a stack of four layers, as a part of the Manipulator Flight Demonstration (MFD) - Evaluation of Space Environment and Effects on Materials (ESEM) experiment (Fig. 9; Kitazawa et al., 1998a). It was located alongside of the MFD pallet and exposed at $316 \mathrm{~km}$ altitude and $51.7^{\circ}$ inclination for about 12 days in total and for 54 hours facing to the velocity vector of the orbiter. After its PFA, no hypervelocity impact signatures were found in the exposed surface. It was not surprising due to its too short mission duration and small exposed area. Only two impactors which apparently hit the aerogel module at extremely low veloci-

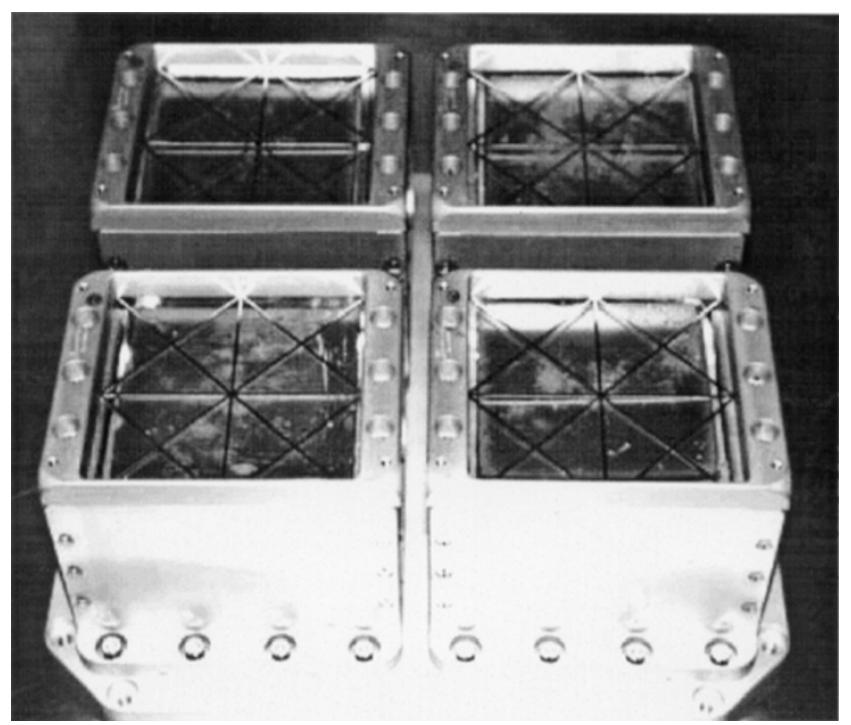

Fig. 9. MFD-ESEM dust collector made of aerogel which was on-board the STS-85 mission (Photo courtesy: NASDA).

ties were discovered. Morphological and elemental analyses suggested that they were debris particles emitted from the shuttle orbiter or/and its other exposed experiments (i.e., not another shuttle mission nor other spacecraft) (Kitazawa et al., 1998a).

\section{An Exposed Payload for the International Space Station}

On the other hand, the MFD-ESEM has proven its spaceflight qualification and led to develop a new Microparticle Capturer (MPAC) module as a part of the Space Environment Data Acquisition Equipment (SEDA), one of the very first four payloads of the Japanese Experiment Module (JEM) Exposed Facility (EF) on the International Space Station (ISS) (Fig. 10; Kitazawa et al., 1998b). The MPAC is yet another passive dust collector made of the same aerogels and other "space-proven" target materials such as Al alloy and gold plates enabling for direct comparison with the previous spacecraft PFA. At this time, the target will be exposed in the ISS operational altitude up to $1 \sim 3$ years from the year 2002 and be retrieved back to the Earth for subsequent laboratory analyses. Larger MPAC aerogel modules will also be exposed on the exterior of the ISS Russian Service module from 2001 and one third of the portion will be returned to Earth every year in the total duration of 3 years.

\section{Hybrid Dust Collector and Detector}

Previous PFAs and simple passive collectors are low-cost, well-established space-proven technology which enable researchers to study impact sites of microparticles with stateof-the-art analytical instruments at ground laboratories. However, their severe disadvantage in terms of to understanding origins of impactors is that they normally can reveal only very limited information of impactors (size and composition in some cases), number of impacts which have impact fluxes averaged out over the integrated exposure time, and impact angles in limited cases. They can hardly retain unambiguous information regarding the impact trajectory, impact velocity, 


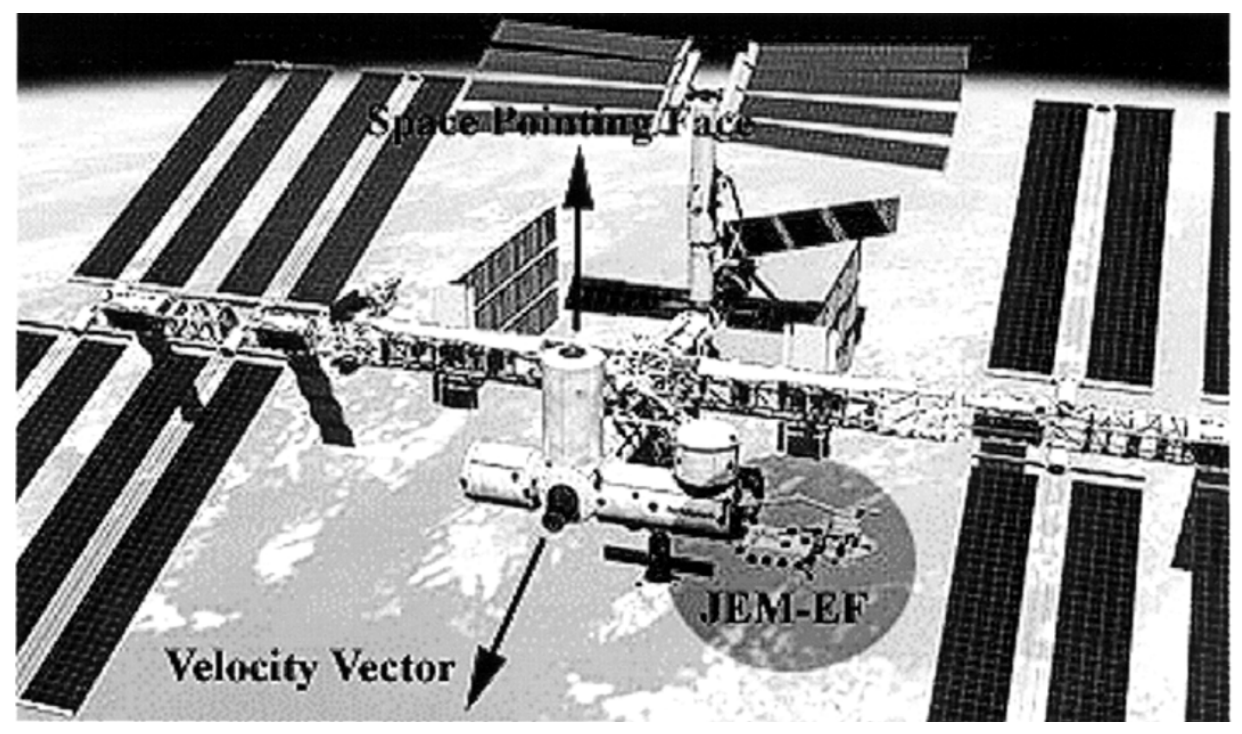

Fig. 10. An artist impression of the JEM-EF on the ISS. Note that the Exposed Facility has open field of views not only to the velocity vector but also to the space and trailing faces where meteoroids can be preferentially collected (Computer Graphic Courtesy: NASA).

impactor mass and shape, and time of impacts, all of which are important parameters to separate meteoroids from orbital debris as well as sub-divide the natural impacts by their parent bodies, i.e., asteroids vs. comets. In fact, active detectors on-board LDEF and the Mir Space Station clearly show that there occur very high flux events such as debris swarms and seasonal meteoroid streams over a month-to-year time frame (Mulholland et al., 1992; Maag et al., 1997).

In order to get these information by in-situ instrumentation in space, there are two options to be pursued. One is real time active detectors being capable of time-of-flight mass spectrometer (TOF-MS) for impact induced plasma to measure elements of impacting particles at the time of impact. Such instruments have been deployed on interplanetary probes such as Helios, Giotto, Vega and Cassini/Huygens and STARDUST spacecraft since 1970's and improved versions are prepared on-board the forthcoming CONTOUR and Rosetta missions. Although potentially being useful to measure flux ratio between meteoroids and space debris, no TOFMS has been utilized for measurement of the near-Earth dust environment so far.

The other option is a dust collector with time resolved function. Several attempts for this concept were made in the past. The Timeband Capture Cell Experiment (TiCCE) was deployed on EuReCa in 1992-1993 (Stevenson, 1988). It was designed to backdate time of impacts from distances between penetration holes on a top thin foil and impact residues on the witness plates underneath along the movement of guiding wires shifted at a constant rate (several $\mathrm{mm}$ per a few days) over the mission. However it was malfunctioned after its first few steps. On the Mir station, "suit-case" type aerogel dust collectors were exposed (Hörz et al., 1998). It could control the exposed duration but did require astronauts to perform extra-vehicular activities (EVA) for opening and closing; thus its time resolution depended upon an interval of the two EVAs and it is not at all a flexible and economical option.

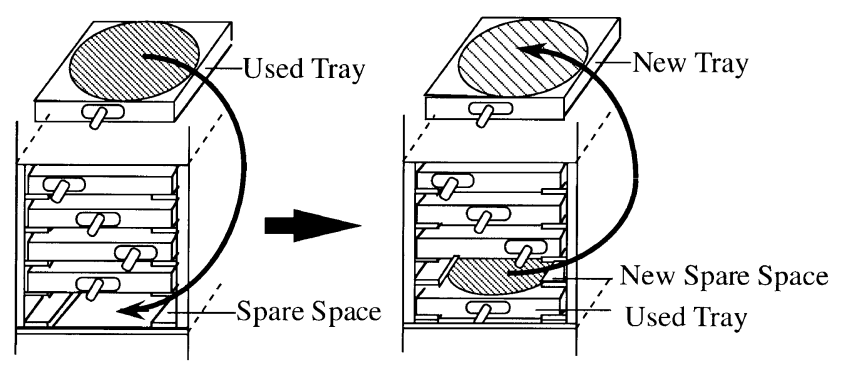

Fig. 11. A drawer-type dust collection system exchanged by the robot arm to expose fresh trays for specific high flux impact events with known origins.

For the ISS, scientists from its international partners also considered similar platforms for time-resolved, retrievable dust collectors with abundant resources on their exposed modules. They include the Cosmic Dust Collection Facility (CDCF) for the NASA Express Pallet (The Steering Committee for the CDCF, 1988), the Dust Watch pop-up system for the ESA-Columbus (Yano et al., 1993), and the Cosmic Dust Collectors and Detectors (CDCD) drawer system (Fig. 11; Yano, 1994), rotating wheel (Fig. 12; Yano and Kitazawa, 1998) and smart passives (Yano and Kitazawa, 1998) for the JEM-EF. Among those, only the JEM-EF can provide inorbit service capability by the robot arm at any given time such that high flux events from known origins can be selected for pre-installed trays, without requiring EVAs. The JEM-EF also provides four exposed faces with respect to the Earth gravity stabilized attitude control of the station (east, west, north and space) in the nominal operation duration of 10 years. The trailing and space faces are where meteoroid impacts exceed artificial debris, thus suitable to study and collect micrometeoroids efficiently.

After a review of the relative merits by Yano and Kitazawa (1998), the aerogel-based hybrid dust collector and detector (HD-CAD) was considered to be as the most favorable con- 


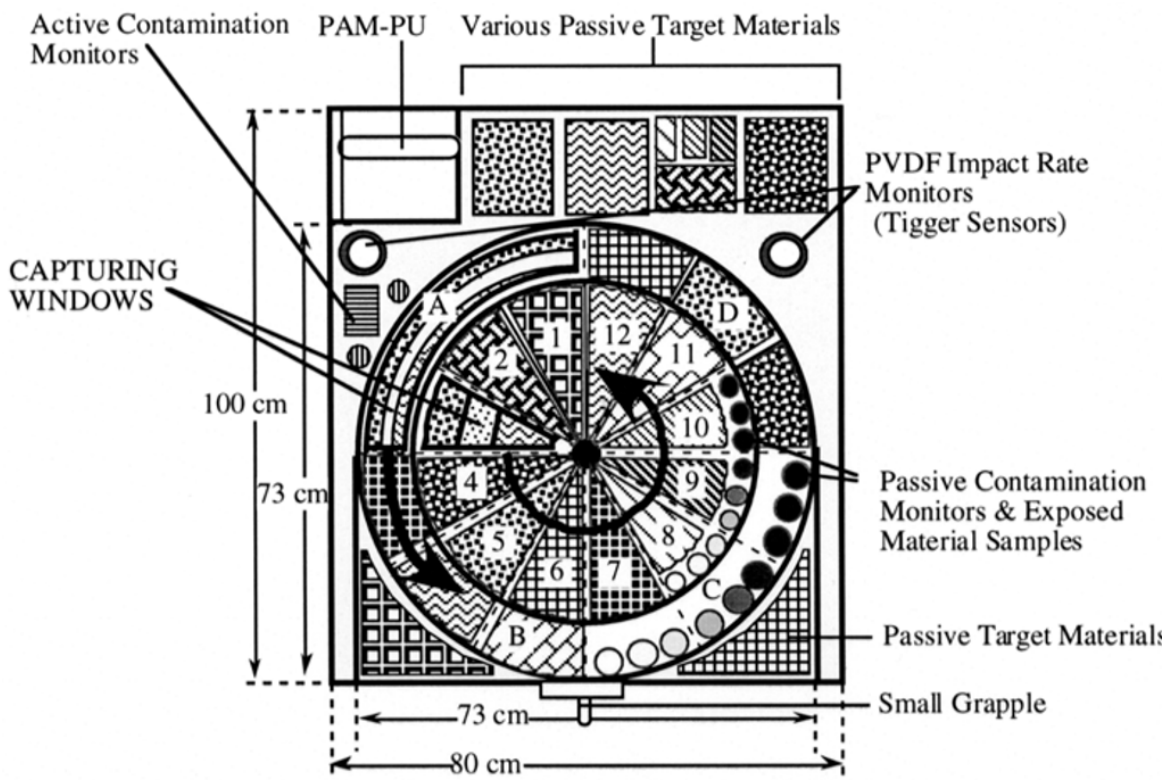

* Outer: Meteoroid Stream Wheel ( $\mathrm{R}=365 \mathrm{~mm}$; 4 Divisions $)$

* Inner: Debris Cloud Wheel ( $\mathrm{R}=265 \mathrm{~mm}$; 12 Divisions)
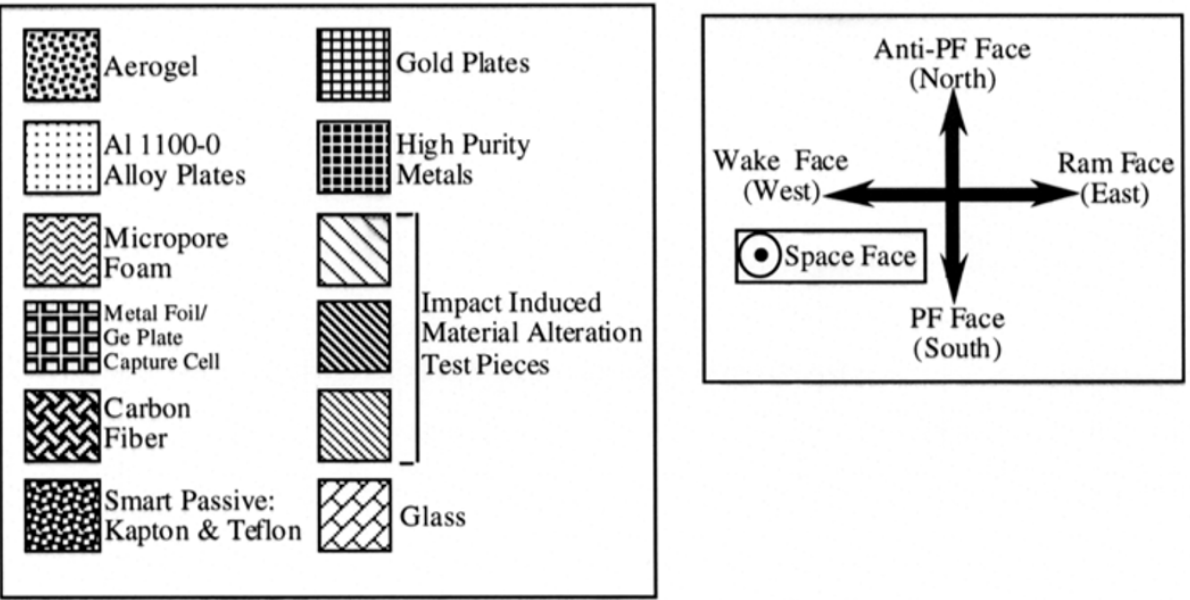

Fig. 12. Rotating wheel system designed for a JEM-EF payload on the space face with various exposed target materials. Keys: PF $=$ pressurized facility; $\mathrm{PVDF}=$ polyvinylidene fluoride; PAM-PU = grapple bar for logistic pallet fixture.

cept to date. It measures the time of impact, energy and velocity (thus estimates mass) of impactors in real time while it still captures particles intact. The aerogel is also used as an impact target that produces impact flash to measure the time of such an event, intensity of flash light as a function of impact energy, its duration, and direction of track excavation. We can reconstruct therefore the impact trajectory by a two dimensional, position sensitive CCD arrays on the bottom and a pair of linear CCD arrays along the sides (Fig. 13). Velocity measurement can be made with both the side CCD arrays and discharge signals by penetration of thin polyvinylidene fluoride (PVDF) films (e.g., $\sim 1 \mu \mathrm{m}$ ) with fast digital data processors (e.g., Nogami et al., 1997). PVDF is a semicrystalline polymer that exhibits strong piezoelectric properties, which produce electric signals due to local mechanical stress, e.g., microparticulate impacts. Initial series of laboratory impact experiments successfully recorded such impact flashes from the aerogels impacted by $25-50 \mu \mathrm{m}$ glass and alumina projectiles at $4.2 \sim 4.6 \mathrm{~km} / \mathrm{s}$ (Yano and Kitazawa, 1998).

The most important advantage of this system over other options is a wide variety of its application. This single system can be used for (1) long duration and continuous monitoring and intact capture of meteoroid and debris on-board LEO spacecraft such as JEM-EF; (2) sample return missions to parent bodies of meteoroids, i.e., comets and asteroids for capturing ejected particles from their surfaces as successors of STARDUST for comets (Vellinga et al., 1997) and MUSES-C for near-Earth asteroids (Kawaguchi et al., 1998) (see the next chapter); and (3) one-way planetary missions which employ an electric propulsion system or/and experience so harsh thermal and plasma environment that impact induced plasma detectors like TOF-MS may suffer from significant noise, such as a Mercury orbiter and a solar probe, as an impact flash detector. 


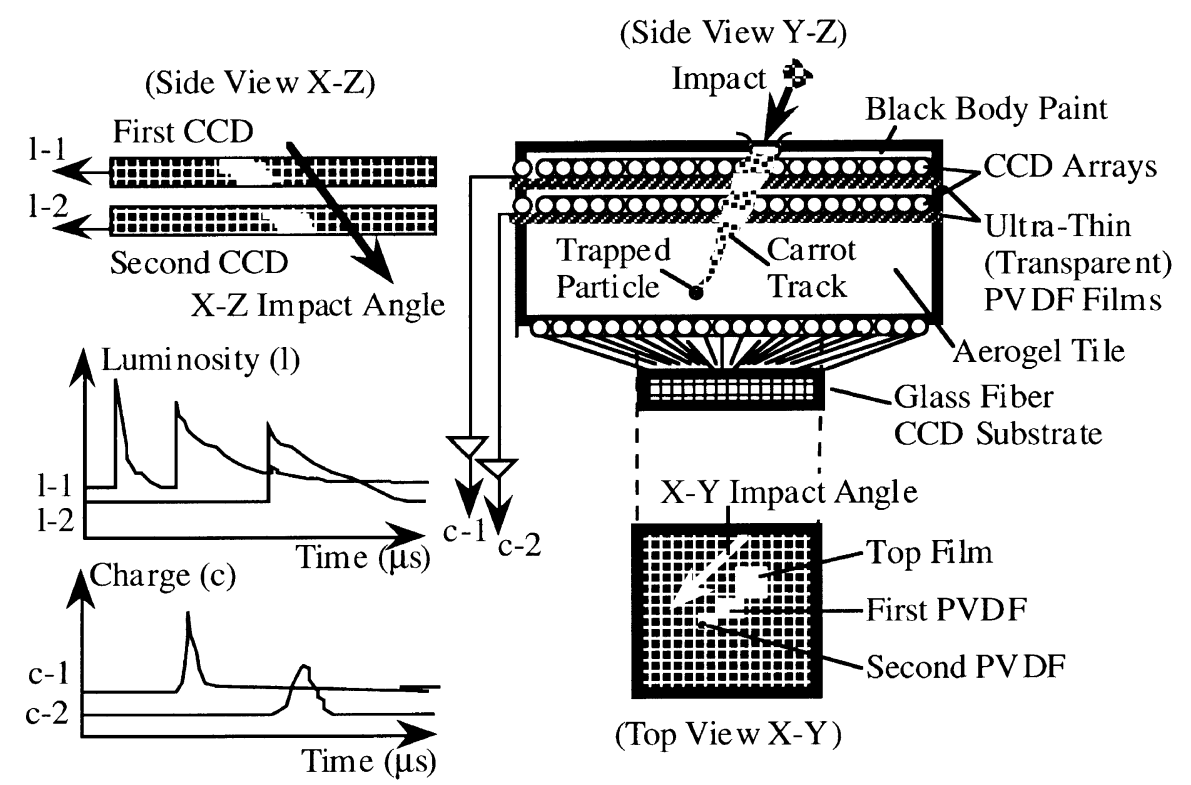

Fig. 13. Concept of the aerogel-based HD-CAD system.

\section{Sample Return Missions to Parent Bodies}

At present, there are hundreds of meteoroid impact craters on retrieved spacecraft components (Yano, 1995), thousands of stratospheric interplanetary dust particles (IDPs) (CDPET, 1982-1994), and some tens of thousands of micrometeorites from polar ice cores (Maurette et al., 1994) collected and studied in the respective curation systems. Some of them were even analyzed mineralogy. Yet we do not even know whether fractal aggregates of sub-micron monomers collected in the stratosphere and partially-melted micrometeorites from Antarctic ice cores share their origins or not. The ratio between asteroidal and cometary dust grains falling to the Earth remains an unsolved question, all because we have not had any dust samples with "ground truth", unambiguous answers of their origins. To achieve this goal and classify a collection of the micrometeoroid/meteorite samples with currently unknown origins, there are two sample return missions to small bodies being prepared: NASA's STARDUST for a comet and ISAS's MUSES-C for a near Earth asteroid. Both missions will collect small grains ejected from their parent bodies in the same mechanisms as their respective meteoroid productions: jetting of gas and dust flow for a comet nucleus (STARDUST) and ejection of spalled surface fragments by impacts for an asteroid (MUSES-C). Size ranges of the samples of both missions are similar to the micrometeoroid/meteorite samples so that consistent analytical procedure and techniques with them should be applied to the STARDUST and MUSES-C samples. Direct comparison of cometary and asteroidal dust grains with trapped meteoroids by the HD-CAD system in the LEO, thus unbiased by the Earth environment, will answer the above question.

\section{Conclusions}

Major results of the present studies and recent developments for future missions in the Japanese space program were reviewed regarding in-situ measurement and collection of micrometeoroids and orbital debris in the near Earth space.
The post flight impact analysis of the SFU satellite has been successfully conducted as its first kind in Japan and had over 700 actual space impact data fully documented. The impacts were classified into natural, man-made, unknown and undetermined origins. The results were consistent with the previously retrieved spacecraft but better records in successful identification of residue contents. The time variation of the microparticulate flux in the LEO seemed to vary from a stationary level where meteoroids exceeded debris to a significant decrease where debris exceeded meteoroids possibly due to shortening of their orbital life times by interaction with the upper atmosphere during the solar activity maximum.

However, it was recognized that in general for most of the retrieved spacecraft data in the past, about a half of impact craters on hard surfaces left no analyzable residues for EDX sensitivity, thus failing to decode the ratio between meteoroids and debris with high confidence. Therefore the next step was to develop intact capture technique for hypervelocity impacts. Following overseas experiments since 1990's, passive aerogel modules were exposed in LEO by NASDA in 1997. This experience led to design yet another microparticle collector to be on-board the ISS Russian service module and the JEM-EF from 2001.

The other disadvantage of the passive dust collectors, even including plain aerogel modules, is the inability to acquire finely time-resolved information and orbital parameters of impactors, which are as important as compositional analysis to determine their origins. Therefore the HD-CAD which overcomes these issues while still capturing particles intact has been introduced and currently been in the development phase. The system is suitable for both sample return missions in LEO as well as to parent bodies of meteoroids and one-way missions to where the thermal and plasma environment is such that impact induced plasma detectors may suffer from significant noise. Although technical challenges to develop this system have found to be not highly demanding (Yano and Kitazawa, 1998), clearly the availability of 
impact simulation facilities for smaller sized and higher velocity impacts than what are available in the present Japanese institutions is the key for its successful realization. For this reason, recently a modification of the Van de Graaff electrostatic accelerator at the University of Tokyo has been made to enable solid, conductive microparticles to be accelerated (Hasegawa et al., 1999). At the time of writing, this facility has achieved acceleration of conductive particles at 3-MV voltage, presently the highest level of this type of facility.

Despite the rich collection of micrometeoroid/meteorite samples for last 20 years, the ratio between asteroidal and cometary dust grains falling to the Earth still remains an unsolved question because there have no samples with unambiguous proof of their origins. To achieve this goal and classify these micrometeoroid/meteorites, currently planned sample return missions to a comet and an asteroid will play a vital role by direct comparison with trapped meteoroids by the HD-CAD system in the LEO.

Acknowledgments. The author is grateful to the SFU Project team (ISAS, NASDA, NEDO/USEF) for supporting the SFU-PFA activities. The SFU-PFA has been co-investigated by S. P. Deshpande, M. J. Neish, K. Morishige, Y. Maekawa and S. Kibe. The author also thanks Y. Kitazawa for useful discussion and his collaboration toward the JEM-EF effort. The Local Organizing Committee of the Western Pacific Geophysical Meeting 1998 is appreciated for their kind invitation to present this work. It is also acknowledged that comments given by referees K. Nogami and J. A. M. McDonnell have improved the content significantly. The author holds a National Research Council (NASA/JSC) Research Associateship.

\section{Appendix A. List of Acronyms}

AMM Antarctic Micrometeorites

C Contamination Only (EDX Analysis Classification)

CCD Charged Couple Device

CDA Cassini Dust Analyzer [Cassini]

CDCD Cosmic Dust Collector/Detector [JEM-EF on ISS]

CDCF Cosmic Dust Collection Facility [ISS]

CDPET Cosmic Dust Preliminary Examination Team

CIDA Cometary Impact Dust Analyzer [STARDUST]

CIMMS Chemical and Isotopic Measurements of Micrometeoroids using SIMS [LDEF]

CONTOUR Comet Nuclei Tour

COSIMA Comet Secondary Ion Mass Analyzer [Rosetta]

D Orbital Debris (EDX Analysis Classification)

DDS Dust Detection System [Galileo]

DFA Dust Flux Analyzer [Rosetta]

DFM Dust Flux Monitor [STARDUST]

DS Deep Space

EDX Energy Dispersive X-ray Spectrum Analyzer

EF Exposed Facility [JEM]

ESA European Space Agency

ESEM Evaluation of Space Environment and Effects on Materials [STS-85]
EuReCa European Retrievable Carrier

EVA Extra Vehicular Activity

FeS-Si Iron, Sulfur and Silicate Bearing (EDX

Analysis Classification)

HD-CAD Hybrid Dust Collector and Detector

HST Hubble Space Telescope

HD-TV High Definition Television

IADC Inter-Agency Debris Co-ordination Group

IDP Interplanetary Dust Particles

ISAS Institute of Space and Astronautical Science

ISS International Space Station

JARE Japan Antarctic Research Expedition

JEM Japan Experiment Module

LDEF Long Duration Exposure Facility

LEO Low Earth Orbit

LV-SEM Low Vacuum-Scanning Electron Microscope

M Meteoroids (EDX Analysis Classification)

MAC Multi-instrument Aircraft Campaign

MDC Mars Dust Counter [Nozomi]

MEEP Mir Environment Evaluation Package [Mir]

MFD Manipulator Flight Demonstration [STS85]

MGS Mars Global Surveyor

MLI Multi-Layer Insulation (or Insulator)

MOS Metallic Oxide Silicon

MPAC Microparticle Capturer [JEM-EF]

MUSES Mu Rocket Series Space Engineering Satellite

N No Residues (EDX Analysis Classification)

NASA National Aeronautics and Space Administration

NASDA National Space Development Agency of Japan

NEAR Near Earth Asteroid Rendezvous

NEDO New Energy and Industrial Technology Development Organization

ODC Orbital Debris Collector [Mir]

PFA Post Flight Analysis

PVDF Polyvinylidene Fluoride

RCS Reaction Control System

SCA Solar Cell Array

SEDA Space Environment Data Acquisition System [JEM-EF]

SELENE Selenological and Engineering Explorer

SEM Scanning Electron Microscope

SFU Space Flyer Unit

SIMS Secondary Ion Mass Spectrometry

SMM Solar Maximum Mission Satellite

SSM Second Surface Mirrors [SFU]

STS Space Transportation System

TiCCE Timeband Capture Cell Experiment [EuReCa]

TOF-MS Time-of-flight Mass Spectrometer

U Undetermined (EDX Analysis Classification)

UDD Ulysses Dust Detector [Ulysses]

USEF The Institute for Unmanned Space Experiment Free Flyer 


\section{Appendix B. List of Nomenclature}

Dc $=$ inner crater diameter $(\mathrm{mm}-\mu \mathrm{m})$ [ductile target]

Dco $=$ conchoidal fracture zone diameter $(\mathrm{mm}-\mu \mathrm{m})$ [brittle target]

Dh $=$ penetration/perforation hole diameter $(\mathrm{mm}$ $\mu \mathrm{m})$

Fmax $=$ the equivalent maximum thickness of an aluminium plate for marginal perforation $(\mathrm{mm}-\mu \mathrm{m})$

\section{References}

Amari, S., J. Foote, P. Swan, R. M. Walker, E. Zinner, and G. Lange, SIMS chemical analysis of extended impacts on the leading and trailing edges of LDEF experiment AO187-2, Proc. Second LDEF Post-Retrieval Symp., NASA CP-3194, 513-528, 1993.

Bernhard, R. P., R. A. Barrett, and M. E. Zolensky, Analytical electron microscopy of LDEF impact residues, Proc. Third LDEF Post-Retrieval Symp., NASA CP-3275, 401-413, 1995.

Brownlee, D. E., F. Hörz, L. W. Hrubesh, J. A. M. McDonnell, P. Tsou, and J. Williams, Eureka! Aerogel capture of meteoroids in space, Abst. Lunar Planet. Sci. Conf., 25(1), 183-184, 1994.

Burchell, M. J., R. Thomson, and H. Yano, Capture of hypervelocity particles in aerogel: In ground laboratory and low Earth orbit, Planet. Space Sci., 47, 189-204, 1999.

Cosmic Dust Preliminary Examination Team (CDPET), Cosmic Dust Catalog, 1-14, NASA/JSC, Houston, Texas, 1982-1994.

Deshpande, S. P., C. R. Maag, S. Kibe, M. J. Neish, and H. Yano, Post-flight contamination assessment/control of the SFU spacecraft, Space Technol., 17(2), 103-112, 1997a.

Deshpande, S. P., M. J. Neish, H. Yano, and S. Kibe, SFU micrometeoroid and space debris impact data archive, Adv. Astronaut. Sci., 96, 1021-1031, 1997 b.

Graham, G. A., A. T. Kearsley, M. M. Grady, and I. P. Wright, The rapid identification of impact residues in the solar array panels of the HST by digitised back-scattered electron \& X-ray elemental imaging, Proc. Second Eur. Conf. on Space Debris, ESA-SP-393, 1997.

Graham, G. A., A. T. Kearsley, M. M. Grady, I. P. Wright, and J. A. M. McDonnell, Micrometeoroid residues collected in Low Earth Orbit, Abst. Lunar Planet. Sci. Conf., 39, 1647, 1998 (on CD-ROM).

Hasegawa, S., A. Fujiwara, H. Yano, T. Nishimura, S. Sasaki, H. Ohashi, T. Iwai, K. Kobayashi, and H. Shibata, Design of accelerators for development of microparticle detectors, Adv. Space Res., 23(2), 367-370, 1999.

Hörz, F., T. H. See, R. Bernhard, and J. Warren, ODC: Aerogel particle capture during 18 months exposure on Mir, Abst. Lunar Planet. Sci. Conf., 29, 1998.

Kawaguchi, J., H. Saito, T. K. Uesugi, and A. Fujiwara, MUSES-C, a technology demonstrator tapping for the asteroid sample return, Presented at the 21 st Int'1 Symp. on Space Tech. and Sci., Saitama, Japan, ISTS 98-0-3-04V, 1998.

Kibe, S., H. Yano, S. P. Deshpande, K. Morishige, Y. Maekawa, K. Imagawa, Y. Arimoto, and M. J. Neish, In-situ debris observation activities in Japan, Acta Astronaut., 1997 (submitted).

Kitazawa, Y., K. Imagawa, Y. Okada, A. Fujiwara, T. Kadono, and R. Amagata, Hypervelocity impact tests and post-flight analysis on MFD dust collectors, Presented at the 21 st Int'1 Symp. on Space Tech. and Sci., Saitama, Japan, ISTS 98-m-14, 1998a.

Kitazawa, Y., R. Amagata, K. Kawachi, K. Fusegi, K. Imagawa, and Y. Okada, Development of the Micro-Particle Capturer on the JEM Exposed Facility, Proc. 14th Space Station. Symp., 105-106, 1998b (main text in Japanese).

Kuriki, K., M. Takei, N. Wakasugi, and T. Yasaka, Meteoroid and Space Debris Impact Investigations in SFU Post Flight Analysis Activities: Preliminary Results and Further Directions, ISAS Report, 666, ISAS, Sagamihara, Kanagawa, Japan, 1997.

Love, S. and D. E. Brownlee, A direct measurement of the terrestrial mass accretion rate of cosmic dust, Science, 262, 550-553, 1993.

Maag, C. R. and W. K. Linder, Results of space shuttle intact particle capture experiments, in Hypervelocity Impacts in Space, edited by J. A. M. McDonnell, pp. 186-190, University of Kent at Canterbury, U.K., 1992.

Maag, C. R., S. P. Deshpande, and N. Johnson, On the existence of debris clouds in the space station orbit-Final results of the EuroMir' 95 impact detector, Proc. Second Euro. Conf. on Space Debris, ESA-SP-393, 201-
205, 1997.

Maurette, M., G. Immel, C. Hammer, R. Harvey, G. Kurat, and S. Taylor, Collection of IDPs from the Greenland and Antarctic ice sheets, in Analysis fInterplanetary Dust, AIP Conf. Proc. 310, edited by M. E. Zolensky, T. L. Wilkinson, F. J. Rietmeijer, and G. L. Flynn, pp. 277-289, AIP Press, 1994.

McDonnell, J. A. M., Microparticle studies by space instrumentation, in Cosmic Dust, edited by J. A. M. McDonnell, pp. 337-426, John Wiley \& Sons, New York, 1978.

McDonnell, J. A. M. and K. Sullivan, Hypervelocity impacts on space detectors: Decoding the space environment (LDEF, MAP A0023 Experiment), Proc. First LDEF Post-Retrieval Symp., NASA CP-3134, 443-458, 1992.

McDonnell, J. A. M., P. R. Ratcliff, S. F. Green, N. McBride, and I. Collier, Microparticle populations at LEO altitudes: Recent spacecraft measurements, Icarus, 127, 55-64, 1997.

Morishige, K., H. Yano, Y. Maekawa, S. P. Deshpande, M. J. Neish, and S. Kibe, Three dimensional analysis of impact crater profiles on the SFU spacecraft's Teflon radiators, Adv. Space Res., 23(1), 113-117, 1999.

Mulholland, J. D., S. F. Singer, J. P. Oliver, J. L. Weinberg, W. J. Cooke, N. L. Montague, J. J. Wortman, P. C. Kassel, and W. H. Kinard, IDE Spatiotemporal impact fluxes and high time-resolution studies of multi-impact events and long-lived debris clouds, Proc. First LDEF Post-Retrieval Symp., NASA CP-3134, 517-527, 1992.

National Research Council (U.S.A.)-Committee on Space Debris/ Aeronautics and Space Engineering Board/Commission on Engineering and Technical Systems, Orbital Debris: A Technical Assessment, 210 pp., National Academy Press, Washington, D.C., 1995.

Neish, M. J., S. P. Deshpande, S. Kibe, H. Yano, Y. Kitazawa, and S. Yamamoto, Micrometeoroid and space debris impacts on the Space Flyer Unit and hypervelocity impact calibration of its materials, Proc. Second Euro. Conf. Space Debris, ESA-SP-393, 177-182, 1997.

Nogami, K., R. Ohmori, and H. Yano, Bombardment of the microparticles on the piezo-film using a two-stage light gas gun, Bull. Gen. Edu. Dokkyo Univ. Sch. of Med., Tochigi, Japan, 20, 31-39, 1997 (main text in Japanese).

See, T. H., M. Allbrooks, D. Atkinson, C. Simon, and M. E. Zolensky, Meteoroid and Debris Impact Features Documented on the Long Duration Exposure Facility: A Preliminary Report, NASA/JSC Publ. No. 24608, Planetary Science Branch Publication No. 84, NASA/JSC, Houston, U.S.A., 1990.

Space Applications Services, UniSpace Kent, Mare Crisium, and ONERA/ CERTS-DERTS, Hubble Space Telescope Micrometeoroid and Debris Post Flight Analysis, Prepared by W. C. Carey, M. Fowler, A. D. Griffiths, J. A. M. McDonnell, J.-C. Mandeville, K. Nichol, A. Quant, N. R. G. Shrine, T. J. Stevenson, E. A. Taylor, and H. Yano, 21 pp., ESA/ESTEC Contract Report, No. 10830/94/NL/JG, ESA/ESTEC, Noordwijk, The Netherlands, 1995.

Stevenson, T. J., Eureca TiCCE-A nine month survey of cosmic dust and space debris at $500 \mathrm{~km}$ altitude, J. Brit. Interplanet. Soc., 41, 429-432, 1988.

Taylor, E. A., N. Shrine, N. McBride, S. F. Green, J. A. M. McDonnell, and G. Drolshagen, Space debris impacts on HST and EuReCa solar arrays compared with LDEF using a new glass-Al conversion, Adv. Space Res., 1999 (in press).

The Steering Committee for the Cosmic Dust Collection Facility (Brownlee, D. E., et al.), Cosmic Dust Collection Facility: Science Objectives and Programmatic Relations, NASA-JSC Report, NASA/JSC, Houston, 1988.

Tsou, P., Silica Aerogel captures cosmic dust intact, J. Non-Crystalline Solids, 186, 415-427, 1995.

UniSpace Kent, Space Application Services, C. R. Maag, Mare Crisium, and ONERA/CERTS-DERTS, EuReCa Meteoroid and Debris Post Flight Investigation, 121 pp., Prepared by I. Collier, A. D. Griffiths, L. Kay, N. R. G. Shrine, and H. Yano, ESA/ESTEC Contract Report, No. 10522/93/NL/JG, ESA/ESTEC, Noordwijk, The Netherlands, 1994.

Vellinga, J. M., C. L. Craig, R. T. Giellis, C. E. Rasbach, J. J. Rogers, M. G. Thornton, W. H. Willcockson, D. E. Brownlee, and K. L. Atkins, Environmental design considerations for STARDUST, Presented at the 27th Int'l Conf. on Environmental Systems, Lake Tahoe, Nevada, USA, July 14-17, 1997.

Warren, J. L., H. A. Zook, J. H. Allton, U. S. Clanton, C. B. Dardano, J. A. Holder, R. R. Marlow, R. A. Schultz, L. A. Watts, and S. J. Wentworth, The detection and observation of meteoroid and space debris impact features on the Solar Max satellite, Proc. Lunar Planet. Soc. Conf., 19, 641-657, 1989. 
Yano, H., Cosmic Dust Collectors and Detectors (CDCD) for the Japan Experiment Module-Exposed Facility (JEM-EF), Proc. the 19th Int'l Symp. on Space Tech. and Sci., 1017-1028, 1994.

Yano, H., The Physics and Chemistry of Hypervelocity Impact Signatures on Spacecraft: Meteoroids and Space Debris, Ph.D. Thesis, University of Kent at Canterbury, 286 pp., Kent, U.K., 1995.

Yano, H. and Y. Kitazawa, Hybrid dust collector and detector for space station and planetary exploration, Proc. the 21st Int'l Symp. on Space Tech. and Sci., 1819-1825, 1998.

Yano, H., P. R. Ratcliff, and J. A. M. McDonnell, Dust Watch as a Model Payload for Columbus-EVP, Proposal for European Space Agency-SPUP Space Station Freedom Columbus Attached Pressurized Module, 1993.

Yano, H., I. Collier, N. R. G. Shrine, and J. A. M. McDonnell, Microscopic and chemical analyses of major impact craters on Timeband Capture Cell Experiment of EuReCa spacecraft, Adv. Space Res., 17(12), 189-192, 1996.
Yano, H., C. Engrand, and M. Maurette, Hypervelocity impact experiments using Antarctic micrometeorites, Antarct. Meteorit., 21, 213-215, 1996.

Yano, H., S. Kibe, S. P. Deshpande, and M. J. Neish, The first results of meteoroid and debris impact analyses on the Space Flyer Unit, Adv Space Res., 20(8), 1489-1494, 1997.

Yano, H., K. Morishige, S. P. Deshpande, Y. Maekawa, S. Kibe, M. J. Neish, and E. A. Taylor, Origins of micro-craters on the SFU spacecraft derived from elemental and morphological analyses, Adv. Space Res., 25(2), 293 298, 1999.

Zolensky, M. E., H. A. Zook, F. Hörz, D. R. Atkinson, C. R. Coobs, A. J. Watts, C. B. Dardano, T. H. See, C. G. Simon, and W. H. Kinard, Interim report of the Meteoroid and Debris Special Investigation Group, Proc. Second LDEF Post-Retrieval Symp., NASA CP-3194, 1993.

H. Yano (e-mail: yano@planeta.sci.isas.ac.jp) 